\title{
ANALISIS FINANCIAL DAN DETERMINASI HARGA PADA RANTAI NILAI TOMAT DI KECAMATAN KAYANGAN KABUPATEN LOMBOK UTARA
}

\section{FINANCIAL ANAL YSIS AND PRICE DETERMINATION OF TOMATTO VALUE CHAIN IN KAYANGAN SUB-DISTRICT NORTH LOMBOK REGENCY}

\author{
I Gusti Lanang Parta Tanaya \\ Program Studi Agribisnis - Universitas Mataram
}

\begin{abstract}
ABSTRAK
Tujuan utama dari penelitian ini adalah untuk menganalisis kinerja finansial rantai nilai tomat dan faktor penentu harga tomat yang dijual pengecer pada rantai nilai. Permintaan akan komoditas tomat terus meningkat seiring dengan pertumbuhan penduduk. Dengan kondisi ini maka penjual selalu berusaha memberikan layanan dan nilai komoditas terbaik bagi pembelinya sepanjang rantai nilai yang terjadi. Analisis rantai nilai adalah alat yang memfasilitasi analisis kegiatan usaha terutama dalam hal kegiatan pembentukan nilai tambah yang berkaitan dengan pemanfaatan faktor produksi, penjualan produk dan pengiriman produk. Penelitian ini menggunakan teknik survei untuk mengumpulkan data dengan wawancarai untuk 60 petani responden dan 36 pedagang perantara menggunakan kuesioner terstruktur. Data dikumpulkan pada tahun 2018 dari 3 desa di Kecamatan Kayangan Kabupaten Lombok Utara (KLU) yaitu Desa Pendua, Santong dan Selengen. Pemilihan desa sampel didasarkan pada area penanaman tomat terluas. Data yang terkumpul dianalisis dengan pemetaan saluran rantai nilai, analisis finansial dan regresi model OLS untuk mengetahui deteminan harga jual tomat pengecer. Hasil analisis menunjukkan bahwa terdapat empat saluran distribusi tomat dari petani ke konsumen, nilai tambah tomat paling tinggi dinikmati oleh pedagang pengumpul desa dan faktor penentu utama harga jual tomat pengecer adalah harga cabai, volume penjualan dan musim. Dari hasil penelitian yang diperoleh maka direkomendasikan agar petani mengatur waktu dan luasan tanam dalam kelompok dan penyuluh memfasilitasi koordinasi antara pelaku rantai nilai.
\end{abstract}

Kata kunci: Rantai Nilai, Tomat, Pengumpul, Pengecer 


\begin{abstract}
The main objective of this research is to analyze the financial performance of the tomato value chain and the determinants of tomato prices that retailers sell in the value chain. Demand for tomato increase continualy along with population growth. With this condition, the seller always tries to provide the best service and highest commodity value to the buyers along the value chain. Value chain analysis is a tool that facilitates the analysis of business activities, especially in terms of value-added activities related to the utilization of production factors, product selling and product delivery. This study uses survey techniques to collect data by interviewing 60 respondents and 36 intermediary traders using a structured questionnaire. Data was collected in 2018 from 3 villages in Kayangan District, North Lombok Regency (KLU), namely Pendua, Santong and Selengen Villages. The selection of sample villages is based on the widest tomato planting area. The collected data were analyzed by value chain channel mapping, financial analysis and OLS model regression to find out the retail price of tomatoes. The analysis shows that there are four tomato distribution channels from farmers to consumers, the highest tomato added value enjoyed by village collectors and the main determinant factors of retailers' tomato selling prices are chili prices, sales volume and season. From the results of the research obtained, it is recommended that farmers set the time and area of planting in farmer groups and government should facilitate coordination among value chain actors.
\end{abstract}

\title{
Keyword: Value Chain, Tomatto, Collectors, Retailers
}

\section{PENDAHULUAN}

\section{Latar Belakang}

Kabupaten Lombok Utara memiliki berbagai komoditas tanaman sayuran yang diproduksi oleh petani kecil yang tumbuh pada berbagai zona agroekologi sebagai sumber pendapatan maupun untuk dikonsumsi. Namun, jenis ini terbatas pada beberapa jenis tanaman dan produksinya terkonsentrasi pada beberapa kantong wilayah. Meskipun demikian, produksi sayuran bervariasi dari membudidayakan beberapa jenis tanaman di halaman belakang rumah tinggal untuk konsumsi rumah tangga hingga produksi skala usahatani untuk pasar lokal dan pasar luar KLU (Tanaya et al., 2016; Ermayana, 2018).

Permintaan terhadap sayuran dari tahun ke tahun terus mengalami peningkatan seiring dengan pertumbuhan penduduk. Sifat-sifat sayuran antara lain sensitif atas perubahan cuaca, mudah busuk atau rusak (perishable) dan dikonsumsi dalam jumlah sedikit tapi terus-menerus. Meningkatkan daya saing produk ini dalam kondisi ekonomi yang hiper kompetitif dan pembeli yang semakin rasional hanya bisa dimenangkan dengan menciptakan dan memberikan nilai yang lebih unggul. Hal ini dapat 
dilakukan dengan cara memahami, menciptakan, memberikan, memenangkan dan mempertahankan nilai pelanggan. Agar berhasil, penjual produk perlu menggunakan konsep rantai nilai dan jaringan penyerahan nilai dalam rantai pasok (Kotler, 2004).

Rantai nilai merupakan alat untuk mengidentifikasi cara-cara untuk menciptakan nilai pelanggan yang lebih besar. Rantai nilai memperlihatkan nilai total dan terdiri atas aktivitas nilai dan margin. Aktivitas nilai adalah aktivitas yang terpisah secara fisik dan teknologi. Sedangkan margin merupakan perbedaan antara nilai total dan biaya kolektif pelaksanaan aktivitas nilai (Porter, 1994).

Analisis rantai nilai adalah alat yang memfasilitasi penyelidikan kegiatan usaha dalam hal peluang penciptaan nilai tambah baru serta peningkatan nilai tambah yang ada berkaitan dengan sumber input produksi, penanganan pasca panen dan pengiriman produk. Dalam rantai nilai pertanian, kegiatan utama adalah memetakan perubahan nilai produk mulai dari pasokan input, budidaya tanaman, pengolahan produksi termasuk pasca panen, penyimpanan, penjualan massal, penjualan eceran, dan konsumsi (Ricketts et al., 2014).

Menurut Morgan et al. (2004), kendala utama dalam rantai pasokan sayuran adalah perencanaan, sosialisasi, pengiriman dan ekspektasi. Sejalan dengan pemikiran di atas Marimin dan Nurul (2011) menyatakan bahwa manajemen rantai pasokan produk pertanian mewakili manajemen proses produksi secara keseluruhan dari kegiatan pengolahan, distribusi, pemasaran, hingga produk yang diinginkan sampai ke tangan konsumen. Hal ini akan mencakup berbagai kegiatan seperti meningkatkan akses terhadap input produksi, mengembangkan kapasitas dan keterampilan sumber daya manusia, meningkatkan kondisi kerja dan produktivitas, memperkuat penyampaian layanan bisnis dan keuangan, memungkinkan aliran informasi, memfasilitasi peningkatan akses pasar (Hamprecht et al., 2005). Hasil akhir analisis rantai nilai adalah rencana tindakan atau matriks implementasi yang mengusulkan berbagai solusi untuk mengatasi peluang dan kendala yang diidentifikasi (ILO, 2007).

Pada rantai nilai tomat baik pembeli dan penjual di wilayah studi biasanya tidak memainkan peran kolektif satu sama lain dan tidak ada kegiatan pengolahan tomat. Tantangan utama yang dihadapi produsen tomat di KLU adalah produksi benih, peluang pasar, fluktuasi pasar, pasca panen, produsen yang tidak dapat menentukan harga dan waktu produksi. Dalam keadaan seperti itu, sebuah studi yang berfokus pada masalah produksi, masalah pemasaran, dan peran dan tanggung jawab pelaku dapat memainkan peran signifikan terhadap peningkatan sistem yang ada. Analisis rantai nilai tomat merupakan proses yang menarik yang belum banyak diteliti di wilayah studi. Lebih jauh lagi, tidak ada penelitian yang dilakukan pada analisis rantai nilai tomat dengan mengukur manfaat ekonomi di sepanjang rantai nilai. Oleh karena itu maka dirasa perlu untuk mengetahui analisis rantai nilai tomat di KLU dengan tujuan (1) untuk memetakan rantai nilai tomat, (2) untuk menganalisis kinerja pelaku rantai nilai, dan (3) untuk mengindentifikasi determinan harga tomat di tingkat pengecer pada rantai nilai. 


\section{METODE PENELITIAN}

\section{Lokasi dan Waktu Penelitian}

Penelitian ini dilakukan pada unit usahatani tomat di Kecamatan Kayangan Kabupaten Lombok Utara pada periode Juli - Desember 2018. Kecamatan Kayangan dipilih karena kecamatan ini memiliki areal tanaman tomat terluas di Kabupaten Lombok Utara. Dari Kecamatan Kayangan dipilih tiga desa yaitu Desa Kayangan, Desa Santong dan Desa Selengen. Lokasi penelitian dipilih secara purposive (sengaja) berdasarkan pertimbangan bahwa ketiga desa tersebut memiliki areal penanaman tomat terluas dibandingkan desa lainnya di Kecamatan Kayangan.

\section{Penentuan Sampel dan Responden}

Pengambilan sampel menggunakan metode snowball sampling yang dimulai dari hulu yaitu petani tomat. Snowball sampling adalah suatu metode pengambilan sampel dengan cara menelusuri sampel berikutnya berdasarkan informasi sebelumnya. Metode ini bisa dilakukan dari hulu ke hilir atau sebaliknya. Petani responden yang dipilih sebanyak 60 orang petani dan responden dari pelaku lainnya ditentukan berdasarkan informasi dari petani atau pelaku diatasnya sampai pada posisi jenuh sehingga diperoleh 14 orang pedagang pengumpul dan 22 orang pengecer. Penambahan untuk responden pengecer dilakukan untuk memenuhi persyaratan jumlah data pada analisis regresi model OLS (Ordinary Least Square).

\section{Jenis dan Metode Pengumpulan Data}

Data yang digunakan dalam penelitian ini adalah data primer dan sekunder. Data primer didapat dari observasi atau pengamatan langsung di obyek penelitian, wawancara mendalam dengan informan dan wawancara dengan responden dengan kelengkapan kuesioner. Data tersebut antara lain data mengenai distribusi nilai tambah yang terdapat pada rantai nilai tomat, serta data-data terkait lainnya. Data Primer yang dikumpulkan adalah:

a. Logistik ke dalam antara lain persediaan dan pengendalian benih, penjadwalan persiapan penanaman dan pemasaran.

b. Operasional yang terdiri atas pemeliharaan tanaman, panen dan pasca panen dan pengolahan hasil, pengawasan dan pengendalian mutu.

c. Logistik keluar antara lain pengumpulan hasil setelah pasca panen, penyimpanan, penerimaan pesanan, perencanaan pengantaran.

d. Evaluasi pelayanan konsumen dalam kelompok tani tomat.

Data sekunder diperoleh dari studi pustaka serta dokumen-dokumen pendukung lainnya. Data tersebut antara lain pustaka mengenai konsep rantai nilai, kajian komoditas tomat, nilai tambah, serta hal-hal terkait marjin tataniaga pertanian. 


\section{Pengolahan dan Analisis Data}

Pengolahan dan analisis data yang digunakan dalam penelitian ini adalah analisis deskriptif termasuk penggambaran peta aliran produk pada rantai nilai tomat, analisis statistik deskriptif, analisis finansial dan analisis ekonometrik dengan metode OLS.

\section{Analisis Rantai Nilai}

Usaha individu pelaku rantai nilai dapat memberi manfaat bagi pelaku yang lain sehingga, rantai nilai mana yang menjadi sasaran sangat bergantung pada masalah penelitian (Kaplinsky dan Morris, 2001). Analisis rantai nilai yang diterapkan untuk penelitian ini adalah pemetaan rantai nilai untuk memahami karakteristik pelaku dan hubungan di antara mereka, termasuk peran masing-masing pelaku dalam aliran tomat, dan tujuan serta volume penjualan. Mengidentifikasi distribusi manfaat yang diperoleh pelaku dalam rantai nilai.

\section{Analisis Kinerja Finansial Rantai Nilai Tomat}

Margin nilai adalah alat terbaik untuk menganalisis kinerja financial rantai nilai di setiap tingkat mata rantai. Nilai margin akan dihitung dengan mengambil selisih antara harga produsen dan harga eceran. Share atau pangsa produsen $\left(P_{p}\right)$ adalah rasio yang biasa digunakan untuk menghitung nilai margin. $P_{p}$ dihitung secara matematis sebagai rasio harga pada produsen terhadap harga konsumen. Secara matematis $P_{p}$ dapat dinyatakan sebagai berikut:

$$
\mathrm{P}_{\mathrm{p}}=\frac{\mathrm{H}_{\mathrm{p}}}{\mathrm{H}_{\mathrm{k}}}=1-\frac{\mathrm{NM}}{\mathrm{H}_{\mathrm{k}}}
$$

Dimana: $\mathrm{P}_{\mathrm{p}}=$ Pangsa Produsen; $\mathrm{H}_{\mathrm{p}}=$ Harga di Produsen; $\mathrm{H}_{\mathrm{k}}=$ Harga di Konsumen; dan NM = Nilai Margin

Menghitung Tingkat Margin (TM) selalu terkait dengan harga akhir yang dibayarkan oleh pembeli akhir dan dinyatakan sebagai persentase (Mendoza, 1995)

$$
\mathrm{TM}=\frac{\mathrm{H}_{\mathrm{k}}-\mathrm{H}_{\mathrm{p}}}{\mathrm{H}_{\mathrm{p}}} \times 100 \%
$$

Tingkat margin pelaku ke $\mathrm{j}\left(\mathrm{TMP}_{\mathrm{j}}\right)$ dihitung dengan cara sebagai berikut:

$$
\mathrm{TMP}_{\mathrm{j}}=\frac{\mathrm{HJ}_{\mathrm{j}}-\mathrm{HB}_{\mathrm{j}}}{\mathrm{HB}_{\mathrm{i}}} \times 100 \%
$$

Dimana $\mathrm{HJ}$ adalah harga jual produk di pelaku ke $\mathrm{j}$ dan $\mathrm{HB}_{\mathrm{j}}$ adalah harga beli produk oleh pelaku ke j. Hal ini juga memberikan indikasi bahwa distribusi kesejahteraan di antara petani dan pelaku rantai nilai. 
Margin keuntungan (MK) juga dihitung dengan cara sebagai berikut:

$$
\mathrm{MK}=\mathrm{NM}-\mathrm{BP} \quad ; \text { dimana BP adalah Biaya Penjualan }
$$

Dengan konsep sejenis maka dapat dihitung tingkat margin keuntungan untuk pelaku ke j $\left(\mathrm{TMP}_{\mathrm{j}}\right.$ ) yang merupakan pengurangan biaya penjualan di pelaku ke $\mathrm{j}\left(\mathrm{BP}_{\mathrm{j}}\right)$ terhadap nilai margin pelaku ke $\mathrm{j}\left(\mathrm{NM}_{\mathrm{j}}\right)$. Sehingga margin keuntungan untuk pelaku ke $\mathrm{j}\left(\mathrm{TMP}_{\mathrm{j}}\right)$ dapat dihitung dengan rumus berikut:

$$
\mathrm{TMP}_{\mathrm{j}}=\frac{\mathrm{NM}_{\mathrm{j}}-\mathrm{BP}_{\mathrm{j}}}{\mathrm{MK}} \times 100 \%
$$

\section{Analisis Ekonometrik}

Analisis ekonometrik dengan model regresi linier berganda (OLS) digunakan untuk menganalisis penentu harga pasar tomat di tingkat petani. Variabel dependen adalah harga tomat yang dipasok petani. Model regresi linier berganda ditetapkan seperti dibawah ini (Greene, 2003).

$$
\mathrm{Y}_{\mathrm{i}}=\beta_{0}+\beta_{\mathrm{i}} \mathrm{X}_{\mathrm{i}}+\epsilon
$$

Dimana:

$Y_{i}$ adalah harga tomat yang dijual dalam satu musim tanam $(\mathrm{Rp} / \mathrm{Kw})$

$X_{i}$ adalah variabel penjelas seperti jarak ke pasar, produksi tomat, pembeli, dll $\beta_{\text {I }}$ adalah parameter yang diestimasi

$\epsilon$ adalah error term

\section{HASIL DAN PEMBAHASAN}

\section{Gambaran Daerah Penelitian}

Kayangan adalah satu dari lima kecamatan di KLU. Kecamatan Kayangan terletak di bagian timur wilayah KLU. Sebagian besar lahan di Kecamatan Kayangan merupakan lahan kering dengan luas lahan mencapai 6.235 ha, lahan sawah 2.733 ha dan 940 ha untuk pekarangan. Batas-batas wilayah Kecamatan Kayangan adalah sebagai berikut:

$\begin{array}{ll}\text { Sebelah Utara } & \text { : Laut Jawa } \\ \text { Sebelah Selatan } & \text { : Kabupaten Lombok Barat } \\ \text { Sebelah Barat } & \text { : Kecamatan Gangga } \\ \text { Sebelah Timur } & \text { : Kecamatan Bayan }\end{array}$

Kecamatan Kayangan terdiri dari 8 desa yaitu Desa Santong, Pendua, Dangiang, Sesait, Gumantar, Selengen, Kayangan dan Salut. Penelitian ini dilakukan di tiga desa yaitu Pendua, Santong, dan Selengen. Ketiga desa ini merupakan pusat produksi hortikultura sayuran di KLU. 


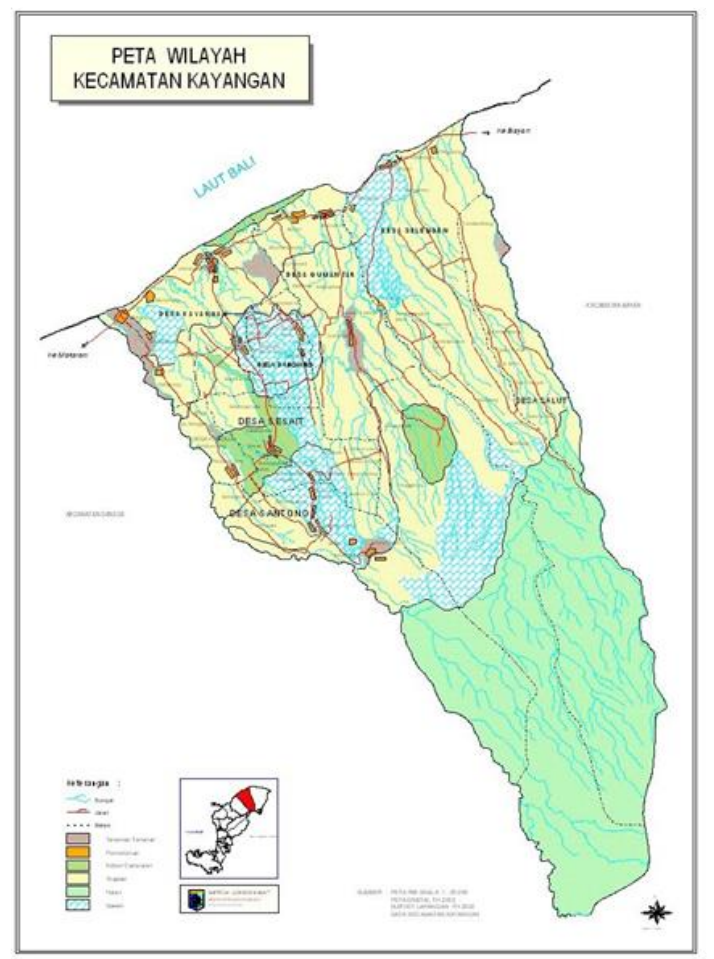

Gambar 1. Peta Kecamatan Kayangan
Kecamatan Kayangan dengan Luas Wilayah $112,90 \mathrm{Km}^{2}$ memiliki jumlah penduduk sebanyak 39264 jiwa. Desa yang memiliki penduduk terbanyak adalah Desa Sesait dengan jumlah penduduk sebanyak 8.371 jiwa, sedangkan desa yang jumlah penduduknya paling sedikit adalah Desa Pendua yaitu sebanyak 2.148 jiwa. Kecamatan Kayangan termasuk wilayah yang beriklim tropis dengan dua musim yaitu musim kemarau yang berlangsung antara bulan April hingga September dan musim penghujan antara bulan Oktober sampai bulan Maret.

Dengan kondisi agroklimat ini maka sebagian besar kecamatan Kayangan merupakan lahan yang cocok untuk pengembangan hortikultura

\section{Karakteristik Responden}

Responden pada penelitian ini adalah petani yang membudidayakan tomat pada musim tanam MK sebanyak 60 orang, pedagang pengumpul di tingkat desa sebanyak 10 orang dan pedagang pengumpul di kabupaten sebanyak 4 orang serta pengecer yang ada di pasar tradisional sebanyak 22 orang. Gambaran tentang karakteristik dari responden ini diuraikan berdasarkan kelompok umur, tingkat pendidikan, pengalaman berusaha, jumlah tanggungan dan luas lahan tomat khusus untuk petani (Tabel 1).

Umur seseorang menentukan kedewasaan orang tersebut. Menurut Mantra (2003), Simanjuntak (2005) dan Subri (2013) umur produktif penduduk di Indonesia berkisar pada umur 15 tahun sampai 64 tahun. Merujuk pada definisi diatas dapat dikatakan bahwa lebih dari 90 persen responden ada pada kisaran umur produktif, bahkan pedagang pengumpul seluruhnya pada usia produktif. Dalam hal penddikan, Sumarsono (2003) dan Simanjuntak (1998) menyatakan bahwa pendidikan seseorang dianggap dapat mewakili kualitas kerja seseorang karena pendidikan dapat meningkatkan pengetahuan dan keterampilan seseorang.

Dalam hal pendidikan, responden memiliki pendidikan formal cukup bervariasi tetapi dapat dikatakan bahwa sebagian besar responden berpendidikan SMP sampai SMA. Secara umum lebih dari 70 persen pendidikan responden SMP dan SMA. Hal yang menarik dari kondisi tingkat pendidikan responden ini adalah pendidikan pedagang pengumpul yang tidak ada tamatan SD kebawah dan pendidikan petani dan pengecer tidak ada 
yang di perguruan tinggi. Terbatas pada rujukan ini dapat dikatakan bahwa kualitas sumberdaya manusia pedagang pengumpul lebih baik dibandingkan dengan petani dan pengecer.

Tabel 1. Karakteristik Rumah Tangga Responden (Angka dalam kurung adalah presentase dari jumlah)

\begin{tabular}{|c|c|c|c|c|c|}
\hline No. & Item & Petani & PPD & PPKab & Pengecer \\
\hline & Kisaran Umur & & & & \\
\hline 1. & $20-34$ & $15(25,00)$ & $1(10,00)$ & & $2(9,09)$ \\
\hline 2. & $35-49$ & $36(60,00)$ & $7(70,00)$ & $2(50,00)$ & $13(59,09)$ \\
\hline 3. & $50-65$ & $6(10,00)$ & $2(20,00)$ & $2(50,00)$ & $5(22,73)$ \\
\hline \multirow[t]{3}{*}{4.} & $>65$ & $3(5,00)$ & & & $2(9,09)$ \\
\hline & Total & $60(100,00)$ & $10(100,00)$ & $4(100,00)$ & $22(100,00)$ \\
\hline & Pendidikan & & & & \\
\hline 1. & Tidak Sekolah & $4(6,67)$ & & & $2(9,09)$ \\
\hline 2. & SD & $12(20,00)$ & & & $4(18,18)$ \\
\hline 3. & SMP & $39(65,00)$ & $1(10,00)$ & & $10(45,46)$ \\
\hline 4. & SMA & $5(8,33)$ & $7(70,00)$ & $3(75,00)$ & $6(27,27)$ \\
\hline \multirow[t]{3}{*}{5.} & PT & & $2(20,00)$ & $1(25,00)$ & \\
\hline & Total & $60(100,00)$ & $10(100,00)$ & $4(100,00)$ & $22(100,00)$ \\
\hline & Pengalaman & & & & \\
\hline 1. & $1-4$ & $20(33,33)$ & $1(10,00)$ & & $2(9,09)$ \\
\hline 2. & $5-9$ & $36(60,00)$ & $6(60,00)$ & $3(75,00)$ & $6(27,27)$ \\
\hline \multirow[t]{3}{*}{3.} & $>9$ & $4(6,67)$ & $3(30,00)$ & $1(25,00)$ & $14(63,64)$ \\
\hline & Total & $60(100,00)$ & 10 & $4(100,00)$ & $22(100,00)$ \\
\hline & Luas Tanam & & & & \\
\hline 1. & $<10$ & $12(20,00)$ & & & \\
\hline 2. & $10-25$ & $39(65,00)$ & & & \\
\hline \multirow[t]{2}{*}{3.} & $>25$ & $9(15,00)$ & & & \\
\hline & Total & $60(100,00)$ & & & \\
\hline
\end{tabular}

Sumber: Data Primer Diolah, 2018

Karakteristik responden terkait pengalaman berusaha sebagian besar memiliki pengalaman lima tahun lebih. Lama berusahatani dapat memberikan pelajaran bagi seseorang agar tidak melakukan kesalahan yang sama sehingga dapat melakukan hal hal yang baik untuk waktu berikutnya (Hasyim, 2003). Dari Tabel 1 tampak masih 33,33 persen petani masih memiliki pengalaman membudidayakan tomat kurang dari 5 tahun walaupun sudah lama menjadi petani. Seluruh PPKab yang menjadi responden seluruhnya memiliki pengalaman lima tahun lebih menjadi pengusaha. Hal ini berarti seluruh responden sudah berpengalaman dalam mengelola usahanya.

Luas tanam tomat hanya untuk petani produsen. Sebagian besar petani menanam tomat dibawah 25 are. Hal ini disebabkan oleh sifat budidaya tanaman sayuran yang umumnya memerlukan biaya tinggi dan sangat berisiko terkena penyakit dan terserang hama. Selain itu risiko ekonomi juga 
menjadi pertimbangan karena harga tomat menjadi sangat murah ketika terjadi panen raya. Bahkan pernah sampai biaya panen tomat lebih besar dari penerimaan petani.

\section{Pemetaan dan Peran Pelaku Rantai Nilai}

Analisis rantai nilai dimaksudkan untuk memberikan pengetahuan yang sistematis tentang aliran barang dari produsen ke konsumen. Rantai nilai adalah konsep yang dapat dengan mudah digambarkan sebagai seluruh rentang kegiatan yang diperlukan untuk membawa produk dari tahap pasokan input melalui berbagai fase kegiatan (produksi, pasca panen, pengolahan) sampai ke pasar akhir. Konsep rantai nilai menekankan pada pentingnya penambahan nilai pada setiap tahap kegiatan dengan demikian memperlakukan produksi hanya sebagai salah satu dari beberapa komponen rantai nilai yang menambah nilai tambah. Aktor utama dalam rantai nilai tomat di Kecamatan Kayangan adalah petani, PPD, PPKab dan Pengecer. Masing-masing aktor ini menambah nilai dalam proses mengubah produk. Beberapa fungsi atau peran dilakukan oleh lebih dari satu aktor, dan beberapa aktor melakukan lebih dari satu peran.

Empat alternatif rantai nilai diidentifikasi untuk distribusi produk tomat ini dari titik produksi hingga produk mencapai konsumen akhir melalui perantara yang berbeda digambarkan pada Gambar 2. Dari Gambar 2 diketahui bahwa sebagian besar tomat petani $(66,8 \%)$ dibeli oleh PPD dan hanya 10,15\% yang langsung dibeli oleh PPKab. Selain itu dapat juga diketahui bahwa sebagian besar tomat petani disalurkan melalui saluran dari Produsen - PPD - PPKab - Pengecer - Konsumen. Saluran yang menyalurkan tomat paling sedikit adalah saluran dari Produsen - PPKab - Pengecer - Konsumen yaitu hanya $10,15 \%$ dari seluruh produksi tomat petani.

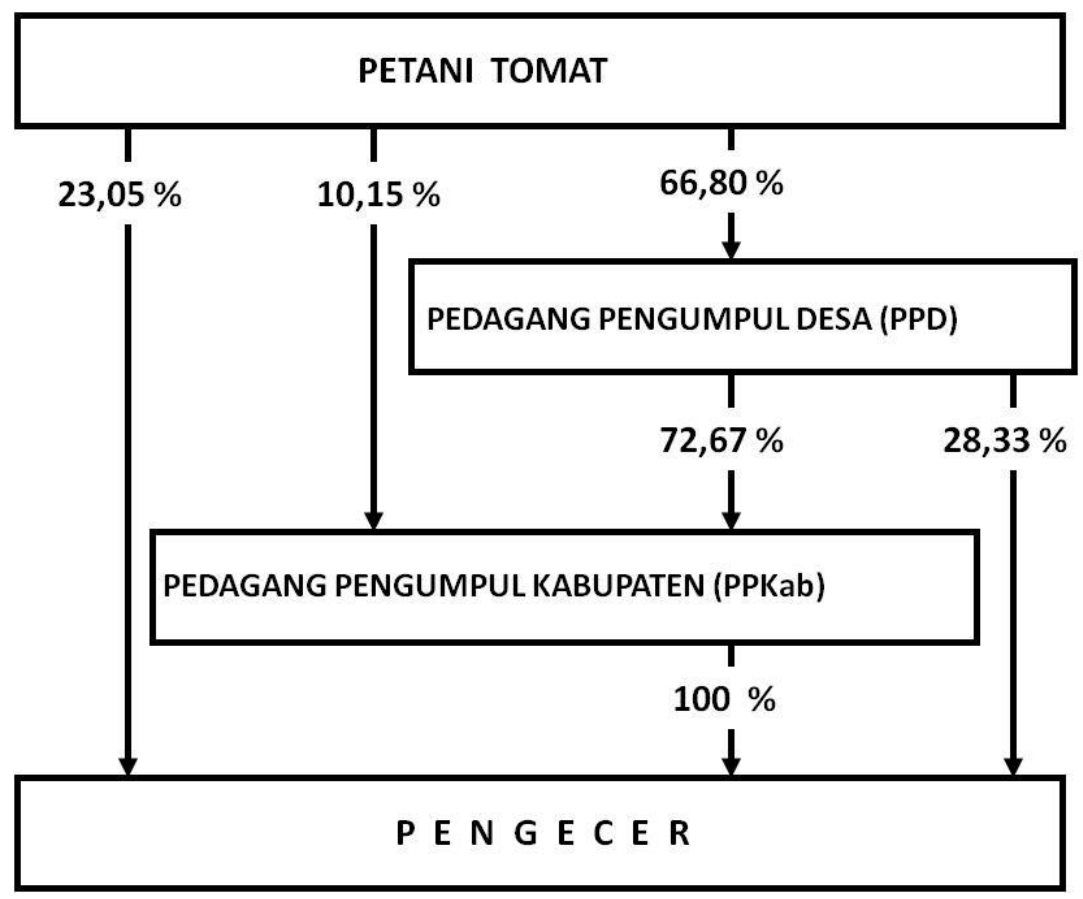

Gambar 2. Aliran Distribusi Tomat 
Masing-masing pelaku rantai nilai menjalankan perannya dalam penambahan nilai tomat pada kegiatan utamanya. Petani mentransformasikan input produksi menjadi komoditas tomat melalui proses usahatani. Selain itu petani juga melakukan peningkatan nilai tambah tomat ini melalui proses pasca panen seperti pemilihan, pemilahan, pengelompokkan dan pengkelasan. Petani hanya memanen tomat yang memiliki tingkat kematangan yang baik. Tomat yang dipanen kemudian dikelompokkan berdasarkan ukuran dan jenis atau varietas tanaman. Pengelompokkan berdasarkan ukuran petani umumnya menggunakan kriteria besar dan kecil. PPD dan PPK melakukan kegiatan penambahan nilai komoditas dengan melakukan pengelompokan berdasarkan warna, bentuk, tekstur daging buah dan keberadaan bekas serangan hama. Beberapa PPD dan satu orang PPKab melakukan juga kegiatan pengepakan sehingga tomat yang dijual oleh pengecer. Pengepakan yang dimaksudkan dalam kegiatan ini adalah pengepakan untuk penjualan dengan harga tertentu tanpa ada standar berat atau volume dan hanya menggunakan kantong plastik kemudian diikat.

Pengecer yang dimaksudkan dalam penelitian ini adalah pengecer tomat yang ada pada pasar tradisional (di Bandung disebut Pasar Becek) yang ada di Pasar Santong, Pasar Tanjung dan Pasar Kebon Roek. Penentuan pengecer ini seperti dinyatakan dalam metode penelitian dilakukan dengan penelusuran berdasarkan informasi dari PPD dan PPKab. Kegiatan yang dilakukan oleh pengecer untuk penambahan nilai komoditas ini sebagian besar pengelompokkan berdasarkan harga per kilogram. Jenis tomat buah mendapatkan harga per kilogram lebih murah dibandingkan jenis tomat sambal (cherry tomato). Demikian juga dengan kesegaran tomat juga dijadikan dasar untuk menentukan harga. Tomat yang sudah lebih dari tiga hari dijual dengan harga yang lebih murah dibandingkan dengan tomat segar. Namun ada dua dari pengecer yang ditemui mencampurkan tomat yang baru datang dengan tomat lama tetapi memberikan harga seperti harga tomat baru.

\section{Analisis Finansial Rantai Nilai Tomat}

Kinerja rantai nilai tomat dievaluasi dengan mempertimbangkan biaya, penerimaan, keuntungan dan nilai margin yang terjadi pada keseluruhan rantai maupun pada masing-masing pelaku rantai nilai. Analisis rantai nilai dimaksudkan untuk memberikan pengetahuan sistematis tentang aliran produk (tomat) dari produsen ke konsumen akhir. Dalam analisis ini distribusi biaya, keuntungan dan nilai margin di berbagai tingkat kegiatan adalah penting dalam rantai nilai tomat ini. Untuk menjadikan tomat yang dijual berkualitas tinggi maka pelaku rantai perlu memberi perhatian yang lebih serius selama panen, pengemasan dan pengangkutan dari titik produksi ke pasar akhir. 
Tabel 2. Distribusi Keuntungan dan Margin Keuntungan pada Aliran Produk Tomat di Kabupaten Lombok Utara

\begin{tabular}{|l|l|r|r|r|r|}
\hline Pelaku & Uraian & \multicolumn{3}{|c|}{ Aliran Produk } \\
\cline { 2 - 5 } & & \multicolumn{1}{|c|}{ I } & \multicolumn{1}{|c|}{ II } & \multicolumn{1}{c|}{ II } & \multicolumn{1}{c|}{} \\
\hline Petani & Biaya Produksi & 2358 & 2358 & 2358 & 2358 \\
& Harga Jual (Hp) & 6450 & 5890 & 5000 & 5000 \\
& Keuntungan (Kp) & 4092 & 3532 & 2642 & 2642 \\
\hline PPD & Harga Beli (HBPPD) & - & - & 5000 & 5000 \\
& Biaya Penjualan (BPPPD) & - & - & 60 & 60 \\
& Harga Jual (HJPPD) & - & - & 6100 & 6100 \\
& Keuntungan (KPPD) & - & - & 1040 & 1040 \\
& Margin Keuntungan (MKPPD) & - & - & 29,29 & 38,58 \\
\hline PPKab & Harga Beli (HBPPKab) & - & 5890 & 6100 & - \\
& Biaya Penjualan (BPPPKab) & - & 110 & 125 & - \\
& Harga Jual (HJPPKab) & - & 7200 & 7350 & - \\
& Keuntungan (KPPKab) & - & 1200 & 1125 & - \\
& Margin Keuntungan (MKPPKab) & - & 43,87 & 31,69 & - \\
\hline PCR & Harga Beli (HBPCR) & 6450 & 7200 & 7350 & 6100 \\
& Biaya Penjualan (BPPCR) & 200 & 215 & 315 & 200 \\
& Harga Jual (HJPCR = Kh) & 7885 & 8950 & 8950 & 7956 \\
& Keuntungan (KPCR) & 1235 & 1535 & 1285 & 1656 \\
& Margin Keuntungan (MKPCR) & 100 & 56,13 & 36,20 & 61,42 \\
\hline Total & Nilai Margin (NM) & 1435 & 3060 & 3950 & 2956 \\
& Margin Keuntungan Total & & & & \\
& (MKT) & 1235 & 2735 & 3550 & 2696 \\
& Biaya Penjualan (BP) & 200 & 325 & 400 & 260 \\
& Tingkat Margin (TM) & 18,20 & 34,19 & 44,13 & 37,15 \\
\hline
\end{tabular}

Sumber: Data Primer Diolah 2018

Catatan: Semua satuan adalah Rp kecuali MK dan TM dalam persen

Biaya pemasaran produk pertanian termasuk tomat pasti akan melibatkan biaya kegiatan pasca panen yang terjadi sebelum mencapai konsumen. Biaya ini termasuk biaya panen dan pengemasan (bahan dan biaya tenaga kerja), penanganan (menyortir, membersihkan, menilai, memuat, dan membongkar), dan biaya transportasi dan pajak. Secara umum, komponen-komponen ini merupakan bagian yang cukup besar dalam mempengaruhi total margin antara harga pada pengecer dan biaya produksi. Perhitungan margin dilakukan untuk menunjukkan distribusi nilai ke berbagai pelaku saat tomat berpindah dari produsen ke pedagang pengumpul (PPD dan PPKab), pengecer dan akhirnya ke konsumen. Hal ini dapat dilihat pada Tabel 2.

Tabel 2 menggambarkan margin harga yang diperoleh dari empat aliran produk dalam rantai nilai tomat di KLU. Margin terendah diperoleh pada saluran terpendek (petani - pengecer) dan tertinggi pada saluran terpanjang. Hal ini sesuai dengan pendapat Kotler dan Amstrong (2003) dan Kotler (2004) yang menyatakan bahwa semakin banyak perantara yang terlibat maka 
margin harga komoditas akan semakin tinggi. Pada rantai nilai tomat ini margin keuntungan pada Saluran III yang terpanjang hampir tiga kali margin keuntungan pada Saluran I.

Hal menarik lainnya yang dapat dicermati dari Tabel 2 diatas adalah distribusi keuntungan yang diperoleh masing-masing pelaku rantai nilai. Secara garis besar pengecer selalu menerima nilai keuntungan tertinggi dan PPD menerima keuntungan terendah. Namun jika dibandingkan dengan keuntungan yang diperoleh petani, secara rata-rata pedagang perantara ini menikmati keuntungan yang lebih tinggi. Dari angka diatas petani belum dapat menikmati $60 \%$ dari selururh keuntungan yang terdistribusi didalam rantai nilai. Dengan demikian maka proses pemasaran tomat di KLU ini belum dapat dikatakan berkeadilan (Anindita, 2004).

Dalam hal margin harga ini, hal yang mirip juga terjadi pada pemasaran komoditas tomat di KLU. Biaya produksi tomat rata-rata Rp. 2358 rupiah per kilogram tomat segar. Biaya ini sudah termasuk biaya saprodi, tenaga kerja, penyusutan alat, sewa lahan dan air irigasi. Usahatani tomat di KLU umumnya dilakukan oleh petani yang mendapat air irigasi dari air permukaan dan air sumur pompa. Kedua jenis air irigasi ini harus dibayar petani dan dimasukkan dalam komponen biaya produksi. Petani menjual tomat ini dengan rata-rata harga Rp. 5585 per kilogram sehingga rata-rata keuntungan di tingkat petani sebesar Rp. 3227 per kilogram. Keuntungan di tingkat petani ini menjadi berbeda sesuai dengan pembelinya. Petani mendapatkan keuntungan tertinggi kalau menjual langsung ke pengecer dan terendah kalau dibeli oleh PPD namun jumlah pembelian oleh PPD sangat banyak dibandingkan dengan pembelian oleh pengecer. Selain itu petani yang mendapat kesempatan menjual ke pengecer hanya petani yang rumahnya atau lahannya berdekatan dengan rumah pengecer.

\section{Determinan Harga Tomat}

Harga tomat yang dimaksudkan dalam tulisan ini adalah harga tomat yang dijual oleh pengecer tomat yang menjadi responden dari hasil penelusuran di sepanjang aliran produk ditambah dengan 18 responden diluar penelusuran aliran produk tetapi diambil dari pasar yang sama. Penambahan responden ini dimaksudkan untuk memenuhi asumsi BLUE (Best liniar unbiased estimation) pada metode OLS yang diterapkan. Sesuai teori permintaan dan penwaran, variabel harga yang diuji pada penelitian ini adalah harga barang komplementer (harga cabai), volume penjualan dan harga barang substitusi (harga terong aceh atau tomato cherry). Komoditas terong aceh dipilih sebagai komoditas substitusi karena semua jenis tomat yang diproduksi responden sepanjang rantai nilai di KLU ini adalah jenis tomat besar. Sebagai informasi, terong aceh sering disebut sebagai tomat sambal dan tomat yang diproduksi responden disebut tomat buah walaupun jenis tomat ini sebagian besar digunakan sebagai bahan sambal.

Dari empat variabel yang diuji, tiga variabel yaitu harga cabai volume penjualan dan musim yang secara signifikan berpengaruh pada harga jual eceran tomat. Gambaran lebih rinci dapat dilihat pada Tabel 3. 
Tabel 3. Hasil Analisis Regresi Linear Terhadap Faktor yang Mempengaruhi Harga Jual Tomat Pada Pengecer di Kabupaten Lombok Utara

\begin{tabular}{|l|c|c|c|}
\hline Variabel & Koefisien regresi & t-hitung & Prob \\
\hline Konstanta & 7836,443 & 6,207 & 0,004 \\
\hline Harga Cabai (Rp/Kg)) & 0,274 & 3,441 & 0,046 \\
\hline Volume Penjualan (Kg/hari) & 256,119 & 4,087 & 0,021 \\
\hline Harga Terong Aceh (Rp/Kg) & $-0,386$ & 1,053 & 0,302 \\
\hline Musim (0 = hujan; 1 = Kemarau) & 1638,024 & 4,995 & 0,036 \\
\hline R-Square & 0,792 & & \\
\hline Adjusted R-Square & 0,735 & & \\
\hline F-hit & 34,128 & & \\
\hline
\end{tabular}

Sumber: Data Primer Diolah dengan Paket SPSS

Tabel 3 menunjukkan bahwa koefisien determinasi $R^{2}=0,792$ yang berarti bahwa kelima variabel mampu menjelaskan faktor-faktor yang mempengaruhi harga tomat pada pengecer di pasar sebesar 79,2 persen dan 20,8 persen disebabkan oleh variabel yang tidak diukur dalam model ini. Hal ini juga didukung oleh Uji $F$ mengetahui pengaruh variabel-variabel yang dianalisis secara bersama-sama (simultan) terhadap harga harga tomat eceran. Analisis uji $\mathrm{F}$ pada tingkat kepercayaan 95 persen memberikan nilai F-hitung sebesar 34,128 lebih besar dari nilai F-tabel sebesar 2,69. Hal ini berarti bahwa harga cabai, volume penjualan, harga terong aceh dan musim produksi berpengaruh nyata terhadap harga jual tomat di pasar. Analisis secara parsial dari masing-masing variabel diuraikan pada bagian di bawah ini.

\section{Harga Cabai}

Koefisien harga cabai pada analisis regresi sebesar 0,274 signifikan $(p=$ 0,046 ) yang berarti bahwa apabila harga cabai mengalami kenaikan sebesar seribu rupiah per kilogram, dengan asumsi variabel independen lainnya bersifat tetap, maka harga jual eceran tomat akan naik sebesar 274 rupiah per kilogram. Hal ini mudah dimengerti karena pada kondisi umum cabai merupakan komoditas komplementer dari tomat. Di Pulau Lombok penggunaan tomat baik untuk sambal maupun untuk sayuran hampir selalu dilengkapi dengan penggunaan cabai.

\section{Volume Penjualan}

Hasil analisis regresi koefisien volume penjualan sebesar 256,119 signifikan $(p=0,021)$ yang berarti bahwa apabila rata-rata volume penjualan tomat di pengecer mengalami kenaikan sebesar $1 \mathrm{~kg}$ per hari maka terjadi kenaikan harga sebesar 256 rupiah per kilogram. Dengan kata lain jika terjadi kenaikan volume penjualan tomat sampai 10 kilogram per hari maka terjadi kenaikkan harga tomat 2560 rupiah per kilogram dengan asumsi variabel independen lain tidak berubah. Sebagai ilustrasi pendudkung bahwa 
pengecer tomat di pasar tradisional tidak ada yang bisa menjual lebih dari 105 kilogram dalam sehari.

\section{Harga Terong Aceh}

Harga terong aceh secara statistik ternyata tidak berpengaruh $(p=0,302)$ terhadap perubahan harga tomat di pasar. Hal ini disebabkan oleh volume terong aceh yang dijual di pasar jauh dibawah volume tomat. Walaupun sifat terong aceh mensubstitusi keberadaan tomat namun karena volumenya sangat sedikit maka keberadaan terong aceh sepertinya tidak berkaitan dengan keberadaan tomat. Selain itu terong aceh hanya menggantikan fungsi tomat pada pembuatan sambal saja tetapi tidak bisa menggantikan tomat untuk jus atau konsumsi tomat segar.

\section{Musim}

Musim yang dijadikan variabel independen dalam penelitian ini adalah musim hujan dan musim kemarau yang dinyatakan dengan variabel dummy. Musim ternyata memberikan pengaruh nyata $(p=0,036)$ terhadap variasi harga tomat di pasar. Harga tomat akan lebih tinggi pada musim penghujan dibandingkan dengan pada musim kemarau. Secara umum petani akan menanam tomat pada musim kemarau atau pada akhir musim penghujan sehingga panen tomat pada musim kemarau. Dengan pola penanaman seperti ini maka pada musim kemarau penawaran tomat menjadi tinggi sehingga harga menjadi turun. Dewasa ini sudah mulai beberapa petani yang menanam tomat pada musim penghujan dengan berbagai macam teknologi seperti plastic tunnel, menggunakan varietas tomat tahan penyakit, pengendalian penyakit sejak masih benih (teknologi benih) dan lain-lain. Dengan keberanian masyarakat menanam tomat di musim hujan ini maka penurunan jumlah tomat pada musim hujan tidak terlalu besar. Namun kualitas tomat yang dijual pada musim hujan sebagian besar lebih jelek dibandingkan tomat yang dijual pada musim kemarau.

\section{KESIMPULAN DAN SARAN}

\section{Kesimpulan}

Terbatas dari hasil dan pembahasan penelitian ini maka dapat disimpulkan beberapa hal yaitu:

1. Petani produsen tomat di Kecamatan Kayangan KLU yang sebagian besar mengusahakan budidaya tomat 25 are kebawah memiliki karakteristik yang mirip dengan pengecer yaitu sebagian besar berumur produktif dan berpendidikan SMP kebawah. Sedangkan pelaku rantai nilai PPD dan PPKab sebagian besar berumur produktif dengan tingkat pendidikan SMA keatas dan memiliki pengalam berusaha lima tahun lebih. 
2. Terdapat empat pelaku utama pada rantai nilai tomat di daerah penelitian yaitu petani (produsen), PPD, PPKab dan Pengecer yang membentuk empat jenis aliran produk yaitu Produsen - Pengecer; Produsen - PPD Pengecer; Produsen - PPD - PPKab - Pengecer; dan Produsen - PPKab - Pengecer. Selain itu diketahui bahwa aliran produk Produsen - PPD PPKab - Pengecer menyalurkan sebagian besar tomat petani dan aliran Produsen - PPKab - Pengecer menyalurkan tomat paling sedikit.

3. Keempat aliran produk yang ada memiliki nilai margin yang berdeda-beda dengan nilai margin tertinggi pada aliran produk terpendek dan nilai margin terendah pada aliran produk terpanjang. Sejalan dengan nilai margin ini, biaya penjualan tertinggi juga ada pada aliran produk terpanjang dan terendah pada aliran produk terpendek. Berlawanan dengan nilai margin dan biaya penjualan, persentase margin keuntungan tertinggi terjadi pada aliran produk terpanjang dan terendah pada aliran produk terpendek.

4. Analisis regresi mengungkapkan bahwa ada tiga faktor yang mempengaruhi harga jual eceran tomat yaitu harga barang komplementer (harga cabai), volume penjualan dan musim.

\section{Saran}

Rekomendasi atau implikasi kebijakan yang dapat ditarik dari penelitian ini didasarkan pada kesimpulan penelitian ini adalah:

1. Menetapkan dan menerapkan kalender tanam untuk tanaman hortikultura di daerah penelitian khususnya dan di KLU umumnya agar jumlah penawaran tomat sepanjang tahun menjadi stabil sehingga harga jual tomat bisa stabil juga. Terkait dengan kalender tanam ini maka direkomendasikan juga agar penyuluh pertanian lapangan bekerjasama dengan BMKG harus mulai mengumpulkan data iklim dan cuaca sebagai dasar pembuatan kalender tanam berdasarkan musim.

2. Belum adanya koordinasi yang baik antara pelaku rantai nilai sehingga terjadi perbedaan margin keuntungan yang cukup besar antara pelaku yang satu dengan yang lainnya. Direkomendasikan agar pihak yang berwenang seperti OPD pemerintah meningkatkan koordinasi antara pelaku rantai nilai melalui pertemuan-pertemuan antara pelaku yang difasilitasi oleh pemerintah.

\section{DAFTAR PUSTAKA}

Anindita, R., 2004. Pemasaran Hasil Pertanian. Papyrus, Surabaya.

Greene, W., 2000. Econometric Analysis. 4th edn. NJ: Prentice Hall, Englewwod Cliffs Ethiopian Agriculture research institute (EARI) 2008.

Hamprecht, J., Corsten, D., Noll, M., dan Meier, E., 2005. Controlling The Sustainability of Food Supply Chains. Supply Chain Management: An International Journal, 10(1), 7-10. https://doiorg/10.1108/1359854051 0578315 diakses 15 September 2012. 
Hasyim, H., 2003. Analisis Hubungan Faktor Sosial Ekonomi Petani Terhadap Program Penyuluhan Pertanian. Laporan Hasil Penelitian, Universitas Sumatera Utara, Medan.

Hasyim, H., 2006. Analisis Hubungan Karakteristik Petani Kopi Terhadap Pendapatan (Studi Kasus: Desa Dolok Seribu Kecamatan Paguran Kabupaten Tapanuli Utara). Jurnal Komunikasi Penelitian. Lembaga Penelitian Universitas Sumatera Utara, Medan.

ILO (International Labor Organization), 2007. Mayoux, L. dan Mackie, G. Making The Strongest Links. A Practical Guide to Mainstream Gender Analysis In Value Chain Analysis. Geneva.

Kaplinsky, R. dan M. Morris, 2001. A Handbook of Value Chain Analysis. Working paper prepared for the IDRC, Institute for Development Studies, Brighton, UK.

Kotler, P. and G. Armstrong, 2003. Principle of Marketing, 10th Edition. Hall of India Pvt. Ltd. New Delhi. pp 5-12.

Kotler, P., 2004. Marketing Management, The Millenium Edition. Englewood Cliffs, New Jersey: Prentice Hall.

Mantra, IB., 2004. Demografi Umum. Pustaka Pelajar, Yogyakarta.

Marimin dan Nurul M., 2011. Aplikasi Teknik Pengambilan Keputusan dalam Manajemen Rantai Pasok, IPB Press, Bogor.

Morgan W, S Iwantoro, AS Lestari, 2004. Improving Indonesian Vegetable Supply Chains. Didalam: GI Johnson dan PJ Hofman, editor. Agriproduct Supply Chain Management in Developing Countries. Proceeding of a Workshop; Bali, 19-22 August 2003. Bali: ACIAR. hlm 139-141

Porter, M., 1994. Keunggulan Bersaing. Jakarta: Bina Rupa Aksara

Ricketts, K.D., C.G. Turvey dan M.I. Gómez, 2014. Value Chain Approaches to Development Smallholder Farmer Perceptions of Risk. https://doi.org/10.1108/JADEE-10-2012-0025 diakses pada 20 Maret 2016

Simanjuntak, P., 2005. Pengantar Ekonomi Sumber Daya Manusia. Penerbit Fakultas Ekonomi UI, Jakarta.

Subri, M., 2003. Ekonomi Sumber Daya Manusia dalam Perspektif Pembangunan. PT. Rajagrafindo Persada. Jakarta.

Sumarsono, S., 2003. Manajemen Koperasi. Graha IImu, Yogyakarta.

Tanaya, IGLP., Sukartono, Taufik, F., Bambang, H.K. dan Nurrahman, 2016. Pengembangan Kawasan Hortikultura Di Kabupaten Lombok Utara Tahun 2016. Laporan Akhir Penelitian, Fakultas Pertanian Universitas Mataram, Mataram 